\title{
If You Need Help, Just Ask: Underestimating Compliance With Direct Requests for Help ${ }^{1}$
}

\author{
Francis J. Flynn \\ Columbia University
}

\author{
Vanessa K. B. Lake \\ Columbia University
}

\begin{abstract}
A series of studies tested whether people underestimate the likelihood that others will comply with their direct requests for help. In the first 3 studies, people underestimated by as much as $50 \%$ the likelihood that others would agree to a direct request for help, across a range of requests occurring in both experimental and natural field settings. Studies 4 and 5 demonstrated that experimentally manipulating a person's perspective (as help seeker or potential helper) could elicit this underestimation effect. Finally, in Study 6, the authors explored the source of the bias, finding that help seekers were less willing than potential helpers were to appreciate the social costs of refusing a direct request for help (the costs of saying "no"), attending instead to the instrumental costs of helping (the costs of saying "yes").
\end{abstract}

Keywords: helping behavior, help seeking, compliance, interpersonal relations

${ }^{1}$ Francis J. Flynn, Columbia Business School, Columbia University; Vanessa K. B. Lake, Department of Psychology, Columbia University.

We wish to thank Dan Batson, Jack Dovidio, Adam Galinsky, and Dale Miller for their helpful comments on this article.

Correspondence concerning this article should be addressed to Francis J. Flynn, who is now at Stanford University, Graduate School of Business, 518 Memorial Way, Stanford, CA 94305. E-mail:

flynn francis@gsb.stanford.edu 
Requesting help is something people do almost every day. However, before seeking help, they often wonder, "If I ask for help, what are the chances I'll get it?" That is, before imposing on someone else for assistance, most people want to know whether that person is likely to say "yes" or "no" in response (DePaulo, 1982). If they believe the potential helper is likely to say "no," they may withhold their request or ask someone else they think would be more likely to agree (Blau, 1955; Lee, 1997). Indeed, the risk of being denied help is real and meaningful, not just because the help seeker is denied valuable assistance but because rejection can be awkward and uncomfortable (Downey \& Feldman, 1996; Goff- man, 1955). Thus, how accurate people are in judging whether someone else will agree to a direct request for help becomes an important concern for social psychologists interested in the determinants of help seeking.

We examined whether help seekers underestimate the likelihood that others will comply with their direct requests for help. Beyond demonstrating this tendency, we considered the underlying psychology of such underestimation. Accurate judgments of compliance require insight on a potential helper's mental state, attitudes, and incentives, but people may not account for all these critical factors. In particular, help seekers may fail to consider a potential helper's difficult position in responding to a request for help. If the potential helper decides to reject the request, she will be violating an implicit norm of benevolence (Brown \& Levinson, 1987; Goffman, 1971; Gouldner, 1960). Although this pressure to comply is salient to the potential helper, it may escape the attention of the help seeker or at least not receive as much consideration. Overlooking this pressure to comply may lead help seekers to underestimate the likelihood that others will say "yes" in response to their requests for help.

Our first three studies examined whether people can accurately predict how successful they will be when soliciting help from strangers. We began with a manufactured favor request, built upon these results with more realistic requests, and finally sought replication in a naturally occurring field setting. In Study 4, we demonstrated the underestimation effect by manipulating the participant's perspective (as help seeker or helper) and asking her to judge the likelihood of compliance in a series of scenarios. In our final two studies, we manipulated the potential helper's level of discomfort in refusing help in order to provide more compelling evidence that help-seekers' failure to account for these feelings of discomfort partly explain their tendency to underestimate others' willingness to comply. Finally, in Study 6, we examined whether help seekers are oblivious to the potential helper's circumstances or whether they focus primarily on one aspect of these circumstances - the instrumental costs helpers incur when providing help. That is, we examined whether help seekers focus more on the costs of saying "yes" rather than the costs of saying "no" when estimating compliance.

These studies extend theory and research in a number of important ways. First, we build on past work on estimating compliance in helping behavior by moving away from cases where the predictor will never pose the request (e.g., Epley \& Dunning, 2000; Milgram \& Sabini, 1978) to cases where estimates are made by the requesters themselves. Second, we provide strong evidence of an underestimation bias in predicting compliance-help seekers believe they are less likely to receive help than is actually the case. Third, we identify the help-seeker's lack of appreciation for the helper's circumstances as a primary source of underestimation, thereby adding to a growing stream of research on the important consequences of attention focus, egocentrism, and perspective taking in helping behavior (Batson, Early, \& Salvarani, 1997; Savitsky, Van Boven, Epley, \& Wight, 2005). Fourth, and more generally, we contribute to a broad scholarly interest in the determinants of helping, demonstrating that people may be more willing to help than others generally assume. 


\section{How Help Seekers Estimate Compliance}

Estimating others' willingness to comply with a request for help requires an understanding of others' motives and incentives to provide assistance. Past research on helping behavior has suggested that help seekers closely attend to the instrumental costs they impose on a potential helper before making a request for help (Greenberg, 1980; Thibaut \& Kelley, 1959). DePaulo and Fisher (1980), for example, found that help seekers were less inclined to request assistance when they felt that the assistance was more inconvenient for helpers to provide. In general, people are less willing to ask for favors that are more burdensome or effortful, even if their need for assistance is legitimate (e.g., Gergen, Ellsworth, Maslach, \& Seipel, 1975; Gross \& Somersan, 1974; Latane \& Darley, 1970; Pruitt, 1968). Such reluctance to pose substantial requests for help is partly driven by an expectation that others are less likely to comply with larger favor requests (DePaulo, 1983). Thus, people likely calibrate their estimates of others' willingness to comply according to their impression of the instrumental costs involved (i.e., others will be less likely to comply as the instrumental costs increase).

Although past research has demonstrated that help seekers attend to the instrumental costs of agreeing to a request for help, these studies have not shown whether and how help seekers attend to the no instrumental costs that potential helpers face. In many cases, people are motivated to comply with a request for help in order to avoid the feelings of embarrassment that might be induced by noncompliance (Baumeister, Stillwell, \& Heatherton, 1994; Milgram \& Sabini, 1978). To date, help-seeking researchers have focused on understanding help-seekers' motivation to avoid feelings of embarrassment but not helpers' motivation to do the same. Does a potential helper's motivation to avoid feelings of discomfort factor into a help-seeker's estimate of compliance? In the following section, we argue that it does not, and we explain how this failure to fully account for another person's motivation to avoid embarrassment may bias help-seekers' predictions of others' willingness to provide help.

\section{Underestimating Compliance with Requests for Help}

Social psychologists have found that people often are mistaken in predicting others' behavior and its underlying causes (Gilbert \& Malone, 1995; Ross, 1977). Given an egocentric view of the world, people tend to believe that others will share their thoughts and feelings, sometimes in spite of contrary evidence (e.g., Epley, Keysar, Van Boven, \& Gilovich, 2004; Nickerson, 1999). They struggle to recognize how others' internal states and intentions may be distinct, even if they have interacted in the past (Ames, 2004). In particular, casual observers may fail to appreciate an individual's concern for potential embarrassment or discomfort as a primary driver of his or her behavior in social interactions. According to Sabini, Siepmann, and Stein (2001), people (particularly Americans) frequently misjudge others because they overlook another person's motivation to avoid discomfort in a face- threatening interaction. Indeed, observers may be oblivious to this need to "save face," even if the observer has experienced the same set of embarrassing circumstances in the recent past.

In the context of helping behavior, help seekers may routinely fail to appreciate another person's concern with rejecting a request for help, despite finding themselves in a similar position on a frequent basis (i.e., most people regularly slip in 
and out of the roles of help seeker and helper; Flynn \& Brockner, 2003). This argument is consistent with research on how people believe they will be judged by others when they have acted inappropriately. Studies have found that people tend to overestimate the likelihood that they will be treated harshly by others, particularly when the focal actor is feeling vulnerable (Swim, Scott, Sechrist, Campbell, \& Stangor, 2003; Woodzicka \& LaFrance, 2001). These exaggerated fears of social rejection are produced, in part, by the tendency to be inordinately focused on one's own misfortunes rather than on factors that could mitigate others' harsh reactions (e.g., Savitsky, Epley, \& Gilovich, 2001). Help seekers might similarly inflate their expectations of harsh treatment (i.e., they anticipate rejection) because they ignore, or at least fail to fully appreciate, others' potential concern for embarrassment or discomfort in responding to a request for help.

We propose that help seekers will underestimate others' willingness to comply with a direct request for help and that such underestimation may stem from the help-seeker's attention focus. For potential helpers, the social costs of saying "no" are salient and aversive, particularly in face-to-face interactions. For help seekers, the potential helper's difficult circumstances (often wanting to say "no" but feeling obligated to comply anyway) may escape their accounting when estimating the likelihood of compliance. Further, even if help seekers do attend to the potential helper's predicament, they may not attach much importance to it because they are not faced with the same set of circumstances (Batson et al., 1997). Given this difference in attention focus-help seekers giving less weight than potential helpers would to the costs of refusing a request for help-we would expect there to be a trend toward underestimating a person's willingness to offer compliance because most help seekers would not fully appreciate that person's motivation to avoid a loss of face (i.e., to avoid saying "no" to a request for help).

\section{Overview and Predictions}

We make two central predictions. First, we believe that people tend to underestimate the likelihood of compliance in posing direct requests for help. That is, help seekers will assume that another person is less likely to agree to provide help than is actually the case. Second, we highlight an underlying psychological mechanism for this effect-that help seekers pay less attention to the social costs of rejecting a request for help than do potential helpers. This discrepancy should correspond to the difference between actual and predicted levels of compliance, so that people who more carefully consider the social costs of saying "no" to a request for help (i.e., how awkward, difficult, and embarrassing it may be to refuse assistance) will be less likely to underestimate an individual's willingness to say "yes."

\section{Study 1}

In Study 1, we tested our main hypothesis that people underestimate whether others will agree to a direct request for help. Specifically, we asked participants to enact the role of help seeker by posing the same request for assistance to several different strangers. Before making their requests, half of the participants predicted the likelihood that those they approached would comply (and the other half made no prediction). 


\section{Method}

\section{Participants}

Fifty-two Columbia University students participated in this study in exchange for \$15. Six participants withdrew voluntarily after reading the task description, 3 additional participants failed to complete the task, and 1 participant never returned to the lab after leaving with the study materials. For our analyses, we focused on the 42 participants who completed the entire study.

\section{Procedure and Design}

At the beginning of the experimental session, participants were given the following instructions: "In this study, you will ask strangers (in person) for a favor. The favor you will be asking them to do is to fill out a paper-and-pen questionnaire that takes approximately 5-10 minutes to complete."

The two-page questionnaires included items from several personality scales (e.g., self-monitoring) and a few questions about the request and the requester. After looking over the questionnaire, participants reviewed a set of guidelines for making their favor requests. First, they had to obtain compliance from five different people in order to complete the task. Second, they could approach only strangers (i.e., they were not allowed to approach people they knew in any way). Third, participants had to adhere to a script when making their request. They could ask only, "Will you fill out a questionnaire?" If pressed for details by the people they approached, participants were instructed to offer minimal information. Fourth, they were required to record the response ("yes" or "no") of every person they approached.

After reviewing the details of the task, half of the participants were randomly chosen to provide estimates of compliance. In other studies, the measurement of actual behavior has often followed the measurement of participants' predictions about such behavior (Goethals, 1986). This may be problematic because predicting one's behavior tends to alter that behavior significantly (e.g., Greenwald, Carnot, Beach, \& Young, 1987; Sherman, 1980). Thus, we asked only half of the participants, "How many people do you think you will have to approach before you get five people to fill out a questionnaire?" The other half of the sample was not asked for a prediction, so that we could determine whether the results were influenced by the act of making a prediction.

Participants were given a clipboard, the questionnaires they would be asking other people to complete, and a tally sheet where they recorded compliance-that is, "Agreed to fill out a questionnaire? $(\mathrm{Y} / \mathrm{N})$ " - gender, and the verbal response of each person they approached. At that point, participants were released onto the campus and told to stay out of view of one another. No more than 5 students were permitted to participate at a particular time to avoid saturating the campus with people asking for identical favors.

Upon returning to the lab with their completed questionnaires, participants were fully debriefed and compensated. As a check on the validity of our data, we asked participants to indicate on a slip of paper whether they had followed all of the instructions while completing the task. Specifically, they were asked to answer "yes" or "no" to the following question: "Did you follow the task instructions completely? That is, were the five questionnaires you handed in filled out by five different strangers?" Participants were told that this act was voluntary and that the slips were anonymous. Before 
indicating their responses, participants were given a private space, and a sealed box was used to collect the completed slips of paper. All but one of the participants chose to complete the slip.

\section{Results}

\section{Predicted Versus Actual Compliance}

Our hypothesis that participants would overestimate the number of people they had to approach in order to complete the task was confirmed. A paired samples $t$-test comparing predicted to actual compliance revealed a significant difference, paired $\mathrm{t}(22)=3.99, p=.001$. In fact, participants overestimated the number of people they thought they would have to approach by approximately twice the number of people they actually needed to approach to complete the task (predicted: $M=20.5, S D=12.3$; actual: $M=10.5, S D=3.9$; see Figure 1 for a summary).

The difference between predicted and actual compliance cannot be explained by the simple act of making a prediction. A one-way analysis of variance (ANOVA) yielded no significant difference between the actual compliance rates of the group that made a prediction $(M=10.5, S D=3.9)$ and the group that $\operatorname{did} \operatorname{not}(\mathrm{M}=11.2, S D=10.2 ; F<1)$.

\section{Validity Check}

Forty-one of our 42 participants completed the anonymous slip asking them to verify the validity of their data. Each of those 41 respondents confirmed that they had followed the task instructions completely, providing us with a positive, albeit rough, indication of the validity of our data.

\section{Discussion}

The results reported here provide some initial evidence that people underestimate others' willingness to comply with a direct request for help. Participants in our study anticipated that they would need to ask approximately twice the number of people they actually needed to ask for help with their task. Although encouraging, one limitation of this preliminary finding is that it is based on an unusual request for help (asking a stranger to fill out a questionnaire). To assess the generalizability of the underestimation effect, we conducted a follow-up study (Study 2) that used two different types of favor requests. In this follow-up study, we also attempted to address a second limitation of Study 1-ensuring that participants completed the task as instructed (rather than simply taking their word for it).

\section{Study 2}

We attempted to replicate our findings from Study 1 by using two alternative favor requests that were more natural: borrowing a cell phone and asking for an escort to a specific destination. For this follow-up study, we adopted the same general paradigm used in Study 1. Participants were asked to make predictions about how many people they would need to ask for a favor before going out onto the campus and approaching strangers with the request. 


\section{Participants}

Forty-eight Columbia University students participated in the study for $\$ 10$ compensation. Participants were recruited through flyers posted around campus.

\section{Procedure}

In this study, participants were assigned to request one of two different favors. They either asked to borrow strangers' cell phones or they asked for an escort to the campus gym. After reading about their task, 13 people withdrew voluntarily leaving us with 35 participants ( 22 women, 13 men). Although this is a fairly high attrition rate, presumably the people who chose not to participate found the task especially daunting (i.e., more difficult to get others to comply with the request for help), thereby making our study a more conservative test of a self-selected group of individuals who felt confident enough to continue.

Borrowing a cell phone. Participants who performed the cell phone task were instructed to approach strangers and ask to borrow their cell phones so that they could make a phone call. The script they were asked to follow each time they approached someone with this request was, "Can I use your cell phone to make a call?" They were instructed not to deviate from this script. If pressed for details, the only information they could offer was that the call "would be quick" and that they needed to "call someone about a psychology experiment." Participants were given the telephone number of the research lab where the study began and informed that they would need to call this number using cell phones borrowed from three different people.

When successful in obtaining the use of another person's cell phone, the participant dialed the lab telephone number and asked to speak to the experimenter. The experimenter recorded the participant's subject number and location on campus before hanging up the phone. If the experimenter did not answer the telephone, the participant was allowed to leave a voicemail message that included the participant's subject number and location on campus. Once a participant called and spoke to the experimenter three times, the participant returned to the lab to complete a follow-up questionnaire.

Any participant who did not call and speak to the experimenter three times was judged not to have completed the task. Four participants who began the task failed to complete it. Two of these participants claimed to have called three times, but on one of their purported calls they failed to speak to the experimenter or leave a voicemail message. One participant left the lab with the study materials and did not return. One participant withdrew voluntarily from the study after being refused by five potential helpers. Only the participants who completed the study are included in the analyses.

Asking for an escort. In the escort group, participants asked for directions and a personal escort to the campus gym. The gym (Dodge Fitness Center) was chosen because its entrance is below campus level and therefore may be difficult to locate. However, the vast majority of Columbia University students know where the gym is located, in part owing to their participation in physical education classes that are required of all Columbia undergraduates. Located in the northwest corner of the main campus, the gym is approximately three street blocks from the middle of campus (a divided walkway called College Walk), where participants were asked to make their requests. 
Participants were once again given a script and instructed to follow it exactly. First, they were told to ask each person whether they were a Columbia student (to ensure that everyone who was asked would know where the gym was). If this person was a student, the participant was instructed to ask, "Can you show me where the gym is?" At this point, potential helpers usually pointed toward the gym or offered verbal directions, in which case our participants were then instructed to ask, "Will you walk me there?" If the potential helper continued to give verbal directions, participants were allowed to say, "I was just over there, and I couldn't find it. Can you take me there?" This complete script was presented to participants before they made their predictions of compliance, and the experimenter reviewed the script with them again as they traveled from the lab to College Walk.

In this study, rather than have participants keep track of the potential helpers' responses, the experimenter shadowed each participant inconspicuously and recorded whether each potential helper complied. When someone agreed to walk a participant to the gym, the experimenter followed the participant and the helper from a distance. The participant was considered to have completed the task when they got one person to escort the participant within sight of the gym, which meant that all participants had to walk a minimum of approximately two blocks with an escort. The participants were informed in advance that they would be shadowed, but they were directed to ignore the experimenter. None of the escorts reported noticing that they had been followed. All participants who attempted the task successfully completed it and, in doing so, faithfully followed the instructions given to them.

\section{Dependent Measures}

After reading about their task in the lab, participants predicted how many people they would need to approach in order to complete it. That is, depending on the task they were assigned, they either predicted how many people they would need to approach before three people agreed to let them borrow a cell phone or one person agreed to walk them to the gym. To get a measure of actual compliance for the cell phone request, we gave participants a tally sheet to carry with them in order to record the yes/no responses of each person they approached with their request. For those instructed to pose the escort request, the experimenter followed each participant and kept track of actual compliance on a tally sheet.

\section{Results}

\section{Predicted Versus Actual Compliance}

Using two different types of favor requests, we replicated our findings from Study 1. Specifically, our hypothesis that participants would overestimate the number of people they would need to approach in order to complete their task was confirmed. Collapsed across both types of favors, participants predicted they would need to approach more people ( $\mathrm{M}=$ $8.61, S D=7.10)$ than they actually had to approach $(M=5.12, S D=2.83), F(1,27)=7.62, p=.01$. This effect did not interact with favor type $(F<1)$, suggesting that participants were overestimating to a similar degree for both favor requests.

Participants in the cell phone group predicted they would have to approach an average of 10.1 people to complete their task of getting 3 people to agree to their request. In fact, they needed to ask only 6.2 people on average, $\mathrm{t}(16)=2.1, p=$ .05. Participants who agreed to perform the escort task predicted they would need to ask an average of 7.2 people to walk them to the gym before 1 person agreed, but they actually had to ask only 2.3 people on average, $\mathrm{t}(11)=3.01, p=.01$ (see 
Figure 1). Furthermore, this error was made by all but 6 of our 29 participants, or $79 \%$ of participants who completed the task and all of the measures.

\section{Discussion}

Study 2 replicated our finding from Study 1-that people tend to underestimate others' willingness to comply with a direct request for help. We extended the generalizability of our findings from Study 1 by using different favor requests, particularly requests that seemed more realistic (borrowing a cell phone and asking for an escort to a specific location). In addition, rather than rely on self-reported compliance with the study instructions, we were able to confirm actual compliance by having an experimenter observe participants for one of the two tasks. Although we have now replicated the underestimation effect using three different types of favors, all three of these requests were contrived, and all three studies demonstrated this effect using a student population. In Study 3, we attempted to generalize these findings to a nonstudent population using a naturally occurring favor request that involves meaningful costs and benefits for the people involved.

\section{Study 3}

In Study 3, we tested whether our predictions would replicate in a natural field setting. To this end, we drew on a sample of volunteers who were asked to solicit donations on behalf of a nonprofit organization. We predicted that these volunteers, like our undergraduate participants in the previous two studies, would underestimate the likelihood that the people they approached would comply with a direct request for help.

\section{Method}

\section{Participants}

One hundred twenty-seven Team in Training volunteers (90 women, 37 men) participated in this study in exchange for a $\$ 25$ contribution to the organization, which counted toward their personal fundraising goal. Participants were recruited through Team in Training information sessions in the New York City metropolitan area and through a series of e-mails sent by local Team in Training organizers.

\section{Team in Training}

Team in Training is a division of the Leukemia and Lymphoma Society, a nonprofit organization that raises money to support clinical research and patient care for various blood cancers. Team in Training helps its volunteers train to run, walk, or bike a marathon, half-marathon, or triathlon by offering a comprehensive endurance sports training program in exchange for their volunteers' fundraising efforts.

To take part in the Team in Training program, volunteers must raise a minimum amount of money (between $\$ 2,100$ and $\$ 5,000$, depending on the race they are training for) by asking others for donations. Those who participate in Team in Training's fundraising programs have several months (on average, 5) to reach their minimum fundraising goal. If any 
volunteer fails to reach her minimum fundraising goal by the deadline, she must either cover the remaining amount on her own or drop out of the program. Most volunteers (around 75\%) reach their minimum fundraising goal without having to expend any of their own resources.

Team in Training offers an appropriate setting to test our predictions for several reasons. First, the request for help in this case occurs naturally-it is not forced or contrived. Second, the magnitude of the request is significant. The average donation obtained by a volunteer in the 2004 season was more than $\$ 50$, and some donations exceeded $\$ 1,000$. Third, the test of our underestimation hypothesis is stringent in this case because the participants have volunteered. Those who volunteered probably assumed they could complete the task or else they would have decided against volunteering. One might reasonably assume that those individuals who opted out of the program would be more inclined to underestimate others' compliance, thereby making the test of our hypothesis more conservative.

\section{Procedure and Design}

We asked Team in Training volunteers who agreed to participate in the study to complete a two-part web-based questionnaire. The first part of the questionnaire was administered before participants began soliciting donations, and the second part was completed shortly after a participant's fundraising deadline had passed. A link to the initial online questionnaire was e-mailed to all Team in Training participants. One hundred twenty-four Team in Training volunteers completed the first questionnaire. Of these participants, 91 completed the second questionnaire, yielding a response rate of $72.4 \%$.

Prequestionnaire. In the prequestionnaire, participants made a number of predictions about their upcoming fundraising task. Specifically, we asked participants to estimate the number of people they would need to approach to complete their fundraising goal, the number of weeks they would need to reach their goal, and the average donation they expected.

Postquestionnaire. After the fundraising deadline had passed, we e-mailed a postquestionnaire to each of the volunteers who had completed the prequestionnaire. Participants were asked to report the number of people they approached for a contribution and the average amount of the contributions made. Participants were also asked to indicate how close they came to reaching their fundraising goal and how much they supplemented their fundraising efforts with their own money, if they needed to do so.

\section{Validity Check}

As a validity check, we compared the mean number of sponsors our participants reported in their postquestionnaire with the number of sponsors recorded in Team in Training's accounting records. The means were not significantly different, paired $t(81)<1$, which gives us some confidence that participants were honest and accurate in the reporting of their fundraising experience. All of our subsequent analyses are based on the numbers that participants reported in the online surveys. 


\section{Predicted Versus Actual Compliance}

We found strong evidence that participants underestimated others' willingness to comply with their direct request for help. Participants predicted they would need to approach significantly more people $(M=210.3, S D=271.2)$ than they actually needed to approach $(M=122.2, S D=118.6)$ in order to reach their fundraising goal, paired $\mathrm{t}(87)=3.13, p=.002$ (see Figure 1). In addition, participants underestimated the average amount that people would contribute, paired $t(90)=$ $3.99, p<.001$. They predicted their supporters would contribute $\$ 48.33$ on average $(S D=\$ 24.83)$, but the average contribution was actually $\$ 63.80$ (SD = \$31.97), 24\% more than the predicted amount. Thus, there seems to be evidence of two different forms of underestimation in this sample-not only were people more willing to comply with a direct request for help than participants had predicted but they were also willing to give more than participants had predicted.

\section{Discussion}

In Study 3, we replicated the effect we found in our previous studies - that people underestimated others' willingness to comply with a direct request for help. In this case, we examined a naturally occurring episode of helping behavior rather than an artificial request. Further, the results of this exercise were meaningful for both the participants (who obtained training assistance) and the people they approached (who made a significant financial contribution). Taken together with the results from our previous studies (Study 1 and Study 2), the cumulative evidence strongly suggests that people believe others are less willing to comply with their direct requests for help than is actually the case. In the studies that follow, we examine the underlying psychological mechanism for this underestimation effect.

\section{Studies 4-6}

Studies 1-3 demonstrated that people are more likely to agree to direct requests for help than help seekers expect. We have proposed that the reason for this underestimation effect is a lack of appreciation for the potential helper's perspective in responding to a request for help. Specifically, those who solicit help fail to fully account for the social pressure facing potential helpers-an obligation to adhere to an implicit norm of benevolence, even when a request for help is made by a stranger.

To test this idea, we conducted two additional studies in which participants were asked to assume the role of either a help seeker or a potential helper in a series of hypothetical scenarios. With this assigned role, participants were asked to make judgments about the average person's willingness to comply with each request. We presumed that participants assigned to the role of the potential helper would predict higher levels of compliance than would those assigned to the role of the help seeker. In addition, we expected participants in the role of potential helper to be more sensitive than participants in the role of help seeker would be to information about the social costs of saying "no" to a request for help.

Finally, in Study 6, we conducted a field study in which we manipulated the social costs of responding to a request for help as well as the instrumental costs. We suspected that help seekers would be more sensitive to instrumental costs (the magnitude of help requested) when estimating the likelihood of compliance (e.g., Miller \& Ratner, 1998) but that actual 
levels of compliance would correspond more to social costs (whether a request is made face-to-face).

\section{Study 4}

In Study 4, we predicted that participants who read a helping scenario written from the perspective of the potential helper would expect higher levels of compliance than would those who read the same scenario written from the perspective of the help seeker. Further, we predicted that participants in the potential-helper role would be more focused on the social costs of saying "no" to a request for help than would participants in the help-seeker role.

\section{Method}

\section{Participants}

Sixty-three Columbia University students participated in this study in exchange for \$5. Participants were recruited by flyers posted around campus.

\section{Procedure and Design}

Participants were randomly assigned to a condition in which they were instructed to assume the perspective of either someone being asked for help or someone asking for help. To reinforce the role assignment, we asked participants to recall and describe (in a few sentences) a recent episode in which they had played their assigned role. For example, those assigned to the help-seeker condition were asked to read the following instructions:

Please take a moment to recall a time recently when someone agreed to do a favor for you. Think about what it was

like to ask for that favor. What did you think? How did you feel? In the space below, please write a few sentences about what the favor request was and what the experience was like (e.g., your emotions, your concerns).

The instructions for those assigned to the potential-helper condition were highly similar but written from the viewpoint of the person being asked for help.

After completing this preliminary task, participants were presented with four scenarios that described different episodes of helping behavior. To avoid a ceiling effect, we tried to describe requests that were inconvenient enough to elicit some variance in reported compliance rates. Each of the scenarios was written from the participant's perspective in the role she had been assigned. For example, participants who were assigned to the potential-helper condition were asked to read the following:

Imagine it's the middle of finals. You've been studying all week for your final exam in a course that's very important to you. You really want to do well. The exam is tomorrow morning. After spending the entire day in the library studying for the exam, you are exhausted. You go back to your dorm room for a bit to take a short break and relax. As you walk in the door, your roommate looks up from her desk. "Would you read my final paper and give me feedback on it tonight?" she asks you.

Those assigned to the help-seeker condition read the same scenario written as follows:

Imagine it's the middle of finals. Your roommate has been studying all week for a final exam in a course that's very 
important to them. They really want to do well. The exam is tomorrow morning. After spending the entire day in the library studying for the exam, your roommate is exhausted. They go back to your dorm room for a bit to take a short break and relax. As they walk in the door, you look up from your desk. "Would you read my final paper and give me feedback on it tonight?" you ask them.

Participants in both conditions were then asked the same set of questions. First, they were asked to estimate the percentage of people who would agree to the request. Second, they were asked three questions having to do with the discomforting circumstances facing the potential helper: (a) How difficult do you think it is to say "no" to this request?; (b) How awkward do you think it would be to say "no" to this request?; (c) How embarrassed do you think one would feel if they said "no"? Responses to these three items were then averaged to create an overall measure of appreciation for the potential helper's awkward position. The coefficient alpha for this three-item scale was .87 .

The other three scenarios involved giving someone a ride home from the airport, letting another person borrow your cell phone, and picking up a package at the post office on behalf of someone else. A summary of the scenarios is reported in Table 1. Each participant was asked to review all four scenarios. Four participants skipped at least one question about the estimated percentage of compliance and are therefore excluded from all collapsed analyses.

\section{Results}

We predicted that ratings of others' willingness to comply would be higher when participants were asked to assume the role of the potential helper rather than the help seeker. Our hypothesis was confirmed. The estimates were submitted to a 2 (role: help seeker vs. potential helper) X 4 (type of scenario) mixed-model ANOVA with repeated measures on the second factor. The interaction was not significant $(F<1)$, suggesting that the pattern of results did not differ according to the content of the individual scenarios. Relevant to the current investigation, a significant main

Table 1

Favor Scenarios for Study 4 in [Potential Helper/Help-Seeker] Formats

Favor
Cell Phone
Imagine [someone is/you're] stuck in Times Square and [they are/you're] running late for a doctor's appointment. [They/you]
try hailing a taxi, but [they're/you're] not having much luck, so [they/you] decide to call [their/your] doctor to let her
know [they're/you're] running late. [They see that you are/you see someone who is] just about to put [your/their] cell
phone away, so [they approach you/you approach them]. "Can I use your cell phone to make a phone call?" [they/you]
ask.
Imagine it's the middle of finals. [You've been/your roommate has been] studying all week for a final exam in a course
that's very important to [you/them]. [You/they] really want to do well. The exam is tomorrow morning. After spending all
day in the library, [you/they] are exhausted. [You/they] go back to your dorm room for a bit to take a short break and
relax. As [you/they] walk in the door, [your roommate looks up from her desk/you look up from your desk]. "Would you
read my final paper and give me feedback on it tonight?" [she asks/you ask].
Imagine that [you are/a friend of yours is] the only one of your friends with a car. Also imagine that it's Friday night and
[you/they] have plans to go out. [You've/they've] been invited to a party tonight by someone [you've/they've] had a crush
on for a while. [You/they] can hardly contain your excitement. As [you're/they're] getting ready for tonight's party, [you
get a phone call/you give them a phone call]. [It's one of your best friends who doesn't have a license/You're one of their
best friends, and you don't have a license]. 'The arrangements I made to pick up my grandmother from the airport tonight
just fell through. Would you pick her up?" [they/you] ask.
Imagine it's the beginning of the school year and [you've been/your friend has been] running around all day long. [You've/
they've] had to wait in line all day at the registrar's office, the bookstore, and the ID office. Finally, all of [your/their]
errands are finished, [you/they] return to [your/their] dorm room, where all [you/they] want to do is relax. [Then you get/
then you give them] a phone call. [It's your friend who is/you are] away on vacation. "The UPS office in Brooklyn is
holding a package that was sent to me. Will you go pick it up for me?" [they/you] ask.


effect of role emerged, $F(1,58)=17.4, p<.001$. On average, people in the potential-helper condition gave higher percentage estimates of compliance compared with people in the help-seeker condition (49.6\% vs. $34.3 \%)$. Looking at the results within each scenario, people in the potential-helper condition gave higher estimates of compliance compared with people in the help-seeker condition in each case. These results are summarized in Table 2.

Finally, we suggested that participants in the help-seeker condition would not only give lower estimates of others' willingness to comply but they would also underestimate the social costs one might incur by refusing to agree. Indeed, this difference was significant across all four scenarios (4.3 vs. 3.4), $\mathrm{F}(1,60)=9.88, p=.003$. As expected, the correlation

Table 2

\begin{tabular}{lcc}
$\begin{array}{l}\text { Predicted Compliance for Potential-Helper Versus Help-Seeker } \\
\text { Conditions by Scenario in Study } 4(N=63)\end{array}$ \\
\hline Scenario and condition & $M$ & \\
\hline$\quad$ Cell Phone & & \\
$\quad$ Potential helper & 57.9 & 32.1 \\
$\quad$ Help seeker & 39.7 & 26.6 \\
Finals & & \\
$\quad$ Potential helper & 54.9 & 25.7 \\
$\quad$ Help seeker & 37.7 & 24.2 \\
Car & & \\
$\quad$ Potential helper & 41.2 & 19.3 \\
$\quad$ Help seeker & 28.8 & 19.6 \\
Package & \\
$\quad$ Potential helper & 45.3 & 26.5 \\
$\quad$ Help seeker & 32.7 & 24.9 \\
All 4 scenarios & & \\
$\quad$ Potential helper & 49.6 & 15.1 \\
$\quad$ Help seeker & 34.3 & 13.3 \\
\hline
\end{tabular}

between the measure of perceived discomfort in refusing compliance and estimated compliance was both positive and statistically significant $(r=.50, p<.001)$, indicating that a failure to perceive others' discomfort in refusing compliance might correspond to a decrease in estimating others' willingness to comply.

A mediation analysis (Baron \& Kenny, 1986) was conducted to test whether the impact that assigned role (help seeker vs. potential helper) had on estimates of compliance was mediated by perceived discomfort in refusing the request. An initial regression model showed that role predicted estimates of compliance, so that those assigned to the potential-helper role gave higher estimates of compliance $(B=-.48, p \leq .001)$. A separate model confirmed that the impact of role on perceived discomfort in refusing the request (i.e., help givers gave higher ratings on the measure of perceived discomfort than did help seekers) was significant ( $B=-.38, p \leq .01$ ). In turn, perceived discomfort in refusing the request predicted estimates of compliance $(\beta=.52, p \leq .001)$. In a combined model, the effect of role on estimated compliance dropped ( $\beta$ $=.33, p \leq .01)$. A Sobel value of $2.33(p=.02)$ suggests that perceived discomfort in refusing the request acted as a mediating variable. However, we would not characterize these results as full mediation because the independent variable remained significant after the mediating variable was included in the same equation. 


\section{Discussion}

The results from this study provide some initial evidence for the mechanism underlying the underestimation effect. We found that when people were asked to assume the role of the potential helper rather than the role of the help seeker, they gave higher estimates of others' willingness to comply. In addition, people in the role of the potential helper gave relatively higher estimates of how discomforting (e.g., awkward, embarrassing) it would be to refuse to comply with a direct request for help compared with those in the help-seeker condition. This perceived-discomfort variable mediated the influence of assigned role on estimated compliance.

Although the results from this study are suggestive, by measuring rather than manipulating social costs, such as embarrassment and awkwardness, the findings are still inconclusive. To address this concern, we conducted a fifth study in which we manipulated the social costs of refusing to provide help.

\section{Study 5}

In Study 5, we manipulated social costs (via directness of the request) in addition to once again manipulating participants' roles in a series of vignettes. Thus, the following study is a 2 (role: potential helper vs. help seeker) $X 2$ (social cost: high vs. low) between-subjects design.

We predicted an interaction whereby participants' estimates of compliance in the potential-helper condition would be higher when the request was made directly (high social-cost condition) than when it was made indirectly (low social-cost condition). In contrast, we predicted that participants' ratings in the help-seeker condition would not vary according to whether the request was made directly or indirectly.

\section{Method}

\section{Participants}

Eighty-three participants completed the study. Fifty-seven participants were Columbia University students recruited by flyers posted around campus who received $\$ 5$ for their participation. The remaining 26 participants were employees of a financial services organization who completed the questionnaire as part of an in-house executive education seminar. The patterns of results for these two groups were nearly identical, so their responses are collapsed in each of our analyses.

\section{Procedure}

As in Study 4, participants were randomly assigned to assume the perspective of either someone being asked for help or someone asking for help. They were presented with four scenarios-one from Study 4 (borrowing a cell phone from a stranger in Times Square) and three new vignettes describing various episodes of helping behavior between strangers, including helping a woman carry a stroller down a flight of stairs to a subway platform, giving up one's seat to a man on the train, and signing a petition for someone running for student government. Each of these scenarios was written from the perspective of either the potential helper or the help seeker.

In addition to manipulating role, we manipulated the social cost of refusing to help by altering the directness of the 
request. For example, in the case of the woman who needs help carrying a stroller down the stairs, the scenario was written to say that she either catches someone's eye and clearly needs help (indirect/low social cost of refusing to provide help) or that she explicitly asks someone for help by saying, "Will you help me with this?" (direct/high social cost of refusing to provide help). Each participant was assigned to a single social-costs condition in which the help requests were made either directly or indirectly. For a summary of the scenarios, please see Table 3. As in Study 4, participants were asked to estimate the percentage of people who would agree to the request.

To test whether the vignettes effectively manipulated feelings of discomfort for the helper, we asked an independent sample of people to read the vignettes from the perspective of the potential helper and then rate the extent to which each scenario engenders feelings of discomfort. Half of the respondents received the direct- request scenarios and the other half received the indirect-request scenarios. For each scenario, we asked them, "How uncomfortable do you think it would feel to avoid helping in this situation?," "How embarrassed would you feel if you decided not to help?," and "How awkward would you feel if you decided not to help?" Using a 7-point scale ranging from 1 = not at all to $7=$ extremely, participants gave higher ratings in the direct-request condition for the uncomfortable item (direct $M=5.377$, indirect $M$ = 4.532), $F(1,124)=14.328, p<.001$, the embarrassed item (direct $M=5.035$, indirect $M=4.143), F(1,125)=16.050, p<$ .001 , and the awkwardness item (direct $M=5.24$, indirect $M=4.294$ ), $F(1,125)=17.51, p<.001$, looking at responses collapsed across scenario.

Table 3

Favor Scenarios for Study 5 in Indirect [Direct] Formats

\begin{tabular}{ll}
\hline Favor & Scenario \\
\hline Cell Phone & $\begin{array}{l}\text { Imagine the following case of a man stuck in Times Square. He is running late for a doctor's appointment. He } \\
\text { tries hailing a taxi, but he isn't having much luck, so he decides to call his doctor to let her know he is running } \\
\text { late. He looks over and sees that you are just about to put your cell phone away. You can tell by his look that } \\
\text { he'd like to use your phone to make a call. ["Can I use your cell phone to make a call?," he asks.] } \\
\text { Imagine that a man has just gotten on the subway and there are no seats available. The man is exhausted and } \\
\text { really wants to sit down. He is standing right in front of you, and he is blantantly scanning the subway car in } \\
\text { the hopes of locating a seat. ["Would you be willing to give up your seat?," he asks you.] } \\
\text { Imagine that a woman is standing at the top of the subway staircase with a baby stroller. She needs someone to } \\
\text { help her carry the stroller down the stairs. She catches your eye as you are walking down the stairs, clearly } \\
\text { hoping you will help her. ["Will you help me with this?" she asks.] } \\
\text { Imagine that a student is planning on running for student government. In order to run, he needs to obtain a number } \\
\text { of signatures on a petition. All of his friends have already signed the petition, so now he needs to start asking } \\
\text { people he doesn't know. He is sitting in the student center and you are sitting reading right next to him. He } \\
\text { strikes up a conversation. "I'm running for student government, and I need people to sign my petition," he says, } \\
\text { hoping you will get the hint. ["Will you sign it?"] }\end{array}$ \\
Student government &
\end{tabular}

\section{Results}

\section{Main Effect of Role}

Looking at the responses given in the direct-request condition, we replicated our main finding from Study 4. Participants who adopted the perspective of the potential helper in a direct-request scenario estimated that a significantly higher percentage of people would comply with the request $(M=63.8 \%)$ than did those assigned to the help-seeker role $(M=$ $50.8 \%), F(1,40)=7.18, p=.01$. 
To test our primary prediction for this study-namely, an interaction of role with directness of the request-the dependent variable of percentage compliance was submitted to a 2 (role: help seeker vs. potential helper) X 2 (directness of request: direct vs. indirect) X 4 (type of scenario) mixed-model ANOVA with repeated measures on the last factor. The three-way interaction of the two between-subjects measures with scenario type was not significant, $F(3,79)<1$, so the pattern of results did not differ by scenario.

We proposed that participants in the potential-helper condition would respond more to the directness of the request than would participants in the help-seeker condition. As predicted, a significant interaction emerged between role and directness, $\mathrm{F}(1,79)=7.3, p=.01$. Participants in the potential-helper condition expected a significantly greater percentage of people to comply with the requests when they were asked directly $(M=63.8 \%)$ than when they were asked indirectly $(\mathrm{M}=52.2 \%), \mathrm{F}(1,38)=6.64, p=.01$. However, this pattern was reversed for participants in the help-seeker condition (direct $M=50.8 \%$, indirect $M=57.6 \%), F(1,41)=1.81, n s$, although this difference was not significant. For a summary, see Figure 2.

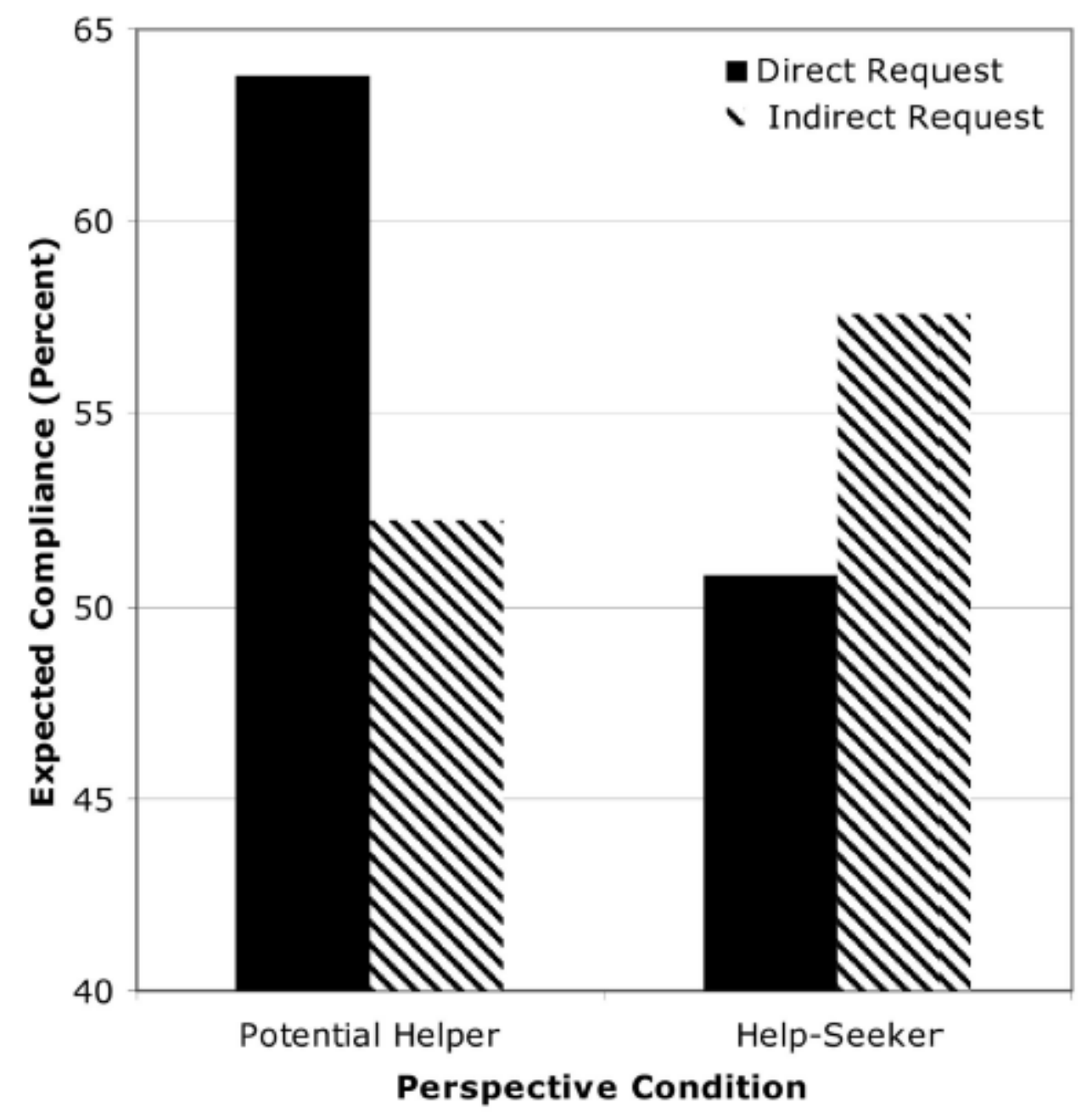

Figure 2. Estimated compliance by role and request directness in Study 5 . 


\section{Discussion}

By manipulating social costs (i.e., the pressure to comply that corresponds to a direct request for help), these results provide additional, more conclusive evidence for our argument that people asking for help pay less attention to the social costs of saying "no" to a request for help than do those who are being asked. In addition, these findings suggest that this difference may act, at least in part, as a mechanism underlying the underestimation effect. When people were asked to assume the role of the potential helper, they gave higher estimates of others' willingness to comply than did people who were asked to assume the role of the help seeker, particularly when the social pressure to comply was more intense.

Although Studies 4 and 5 support our claim that potential helpers pay more attention to the face-saving costs of saying "no" to a direct request for help than do help seekers, these studies rely on hypothetical scenarios. In our final study, we attempted to replicate these effects by returning to the original experimental design used in Study 1 (i.e., asking strangers to fill out questionnaires). We manipulated the face-saving costs of saying "no" to this request by having participants either make their requests face-to-face as they did in our original paradigm (a high social-cost condition) or by handing out a flyer with the request printed on it (a low social-cost condition). In addition, we manipulated the size of the request (e.g., instrumental costs) to explore what information help seekers may be attending to instead of social costs. We expected that help seekers would account for the magnitude of a help request in estimating compliance more so than they would the potential discomfort of refusing to help.

\section{Study 6}

Given that it is easier to say "no" to a request that is indirectly, rather than directly, solicited, we expected to find lower actual compliance rates in response to indirect requests than in response to direct requests. However, because we have argued that help seekers do not pay attention to the social costs of saying "no" to a request for help, we expected that our participants would not adjust their predicted compliance rates accordingly. Instead, we hypothesized that helpseekers' estimates of compliance would depend on the instrumental costs of saying "yes" to a request for help (the magnitude of the request) rather than the social costs of saying "no" (the directness of the request).

\section{Method}

\section{Participants}

Ninety-nine Columbia University students participated in this study in exchange for \$10. Sixteen participants withdrew voluntarily after reading the task description, and 4 additional participants failed to complete the task. There were no differences in dropout rates by condition, $\mathrm{x}^{2}(3, N=16)=3.5, p=.32$. Only the 79 participants who completed the entire study are included in our analyses.

\section{Procedure and Study Design}

Participants were informed that they would be asking strangers to fill out questionnaires. Half of our participants were told they would be making this request face-to-face, and the other half were told they would be handing out flyers with 
this request printed on them. In addition, half of our participants were told they would be asking strangers to fill out a 1page questionnaire, and the other half were told they would be asking people to fill out a 10-page questionnaire. Before making their requests, all participants were asked to predict how many people they would have to ask (or hand flyers to) before three people would agree to fill out a questionnaire. We then recorded how many people participants actually had to ask (or hand flyers to) before three people filled out a questionnaire.

We were interested in how accurate participants' predictions were compared to the actual compliance rates by condition. Thus, this study is a 2 (request directness: direct request vs. flyer) X 2 (request size: 10 page vs. 1 page) X 2 (compliance rate: predicted vs. actual) mixed-model design.

To examine the underlying mechanism for our predicted results, we also asked participants to rate how difficult, awkward, and embarrassing it would be to say "no" to the request on a 7-point scale ranging from $1=$ not at all to $7=$ extremely. The coefficient alpha for these three items was .84, so we averaged the responses in order to create a single perceived social-costs scale.

\section{Direct-Request Condition}

The procedure for this condition was identical to that used in Study 1. At the beginning of the session, participants were given the following instructions: "In this study, you will ask strangers (in person) for a favor. The favor you will be asking them to do is to fill out a [1-page/10-page] paper and pen questionnaire."

Participants then reviewed a set of guidelines for making their requests (the same guidelines that are outlined in Study 1) and a copy of the questionnaire they would be asking people to fill out. After reading about their task, participants were asked to predict how many people they thought they would need to ask before three people agreed to fill out a questionnaire (1-page or 10-page). At that time, they also answered the questions about perceived social costs. Before leaving to make their requests, participants were provided with the questionnaires they would be asking other people to complete, a tally sheet where they recorded the response of each person they approached, and a copy of their instructions.

\section{Flyer Condition}

The flyer condition followed the same general procedure as the direct-request condition. However, participants in the flyer condition read the following instructions:

In this study, you will ask strangers for a favor. The favor you will be asking them to do is to fill out a [1-page/10-page] paper-and-pen questionnaire. The way you will be asking them for this favor is by handing out flyers.

Participants were given a set of guidelines for handing out flyers. As in the direct-request condition, they were restricted to soliciting strangers, not people they knew in any way. Unlike the direct- request condition, participants were prohibited from speaking. Instead, they were instructed simply to hand out the flyers and walk away. After reading these instructions and looking over a sample flyer with a questionnaire attached to it, participants were asked how many flyers they thought they would have to hand out before three people would agree to fill out the attached questionnaire. Following this question were the three items about how difficult, awkward, and embarrassing they thought it would be to say "no" to 
this request.

After providing their estimates, participants were handed a stack of 25 flyers with either 1-page or 10-page questionnaires. Printed on the flyers was the request, "Will you fill out a [1-page/10-page] questionnaire?" This is the same script that participants were asked to use in the direct-request condition. Directly underneath this request were instructions for the people who received the flyers to return their completed questionnaires to a collection box located in the front entrance of the Columbia psychology department.

In one condition (the 10-page questionnaire/flyer condition), participants' estimates of how many people they would have to approach before three people agreed to fill out a questionnaire $(M=31.45)$ exceeded the number of flyers (25) they were given to hand out. To create a measure of accuracy that was consistent across conditions, we divided all participants' predictions by 3, providing us with an approximate estimate of how many people participants thought they would have to approach before one person would agree to fill out a questionnaire. We adjusted our actual compliance measure accordingly by recording how many people participants actually had to ask (or hand flyers to) in order to get one person to fill out a questionnaire. For the three conditions where we could look at predicted versus actual compliance for getting three people to fill out a questionnaire, the data were identical when we analyzed them using the singlequestionnaire measure. Thus, all of our results are reported as predicted and actual compliance rates for getting one person to fill out a questionnaire.

Participants' subject numbers were printed on the back of each questionnaire so that we could track which participant's questionnaires were returned to the collection box. We also numbered each participant's questionnaires from 1 to 25 . To measure how many flyers each participant handed out before one of their questionnaires was returned, we recorded the lowest numbered questionnaire that was returned. If, for a given participant, questionnaires \#12, \#17, and \#22 were returned, that participant was considered to have handed out 12 flyers before one person completed a questionnaire. If no questionnaires were returned for a given participant, we used " 25 " as the number of flyers he or she had to hand out before one person agreed to fill out a questionnaire, which makes the test of our hypotheses more conservative. Five participants (25\%) from the 1-page questionnaire condition and 7 participants (35\%) from the 10-page questionnaire condition had no questionnaires returned.

\section{Materials}

The questionnaires in the flyer and direct-request conditions were identical. Both the 1-page and the 10-page questionnaires contained filler items from various personality scales (e.g., self monitoring, Big Five). The first page of the 10-page questionnaire was identical to the 1-page questionnaire. 


\section{Predicted Versus Actual Compliance by Condition}

To examine how participants' predictions compared to actual compliance rates across the four conditions, we submitted our data to a 2 (directness: flyer vs. direct request) X 2 (size: 10 page vs. 1 page) X 2 (compliance: predicted vs. actual) mixed-model ANOVA with repeated measures on our compliance variable. The only significant interaction that emerged from this analysis was a Directness $X$ Compliance interaction, $F(1,75)=26.4, p<.001$. This interaction reflects the fact that we replicated our original overestimation effect in the direct-request condition (predicted $M=5.22$, actual $M=2.28$ ), but in the flyer condition, the effect was reversed (predicted $M=7.58$, actual $M=15.32$ ).

This pattern was the same regardless of the size of the request. In the 1-page direct-request condition, participants predicted that they would have to approach more people $(M=3.95)$ than they actually had to approach $(M=1.71)$ before one person agreed to fill out a questionnaire, $\mathrm{t}(20)=2.38, p=.03$. However, in the 1-page flyer condition, participants predicted that they would need to hand flyers out to fewer people $(M=4.68)$ than they actually had to hand them out to before one person filled out a questionnaire $(M=14.65), t(19)=-4.95, p<.001$. With 10-page questionnaires, we saw the same pattern. That is, participants in the direct-request condition predicted they would have to ask more people (M $=6.49)$ than they actually had to ask $(M=2.84)$ in order to get one person to fill out a questionnaire, $\mathrm{t}(18)=3.19, p=.005$. Finally, in the 10-page flyer condition, participants once again predicted they would have to hand flyers out to fewer people $(M=10.01)$ than they actually needed to $(M=15.80), t(19)=-1.77, p=.093$. See Figure 3 for a summary of predicted and actual values across all four conditions.

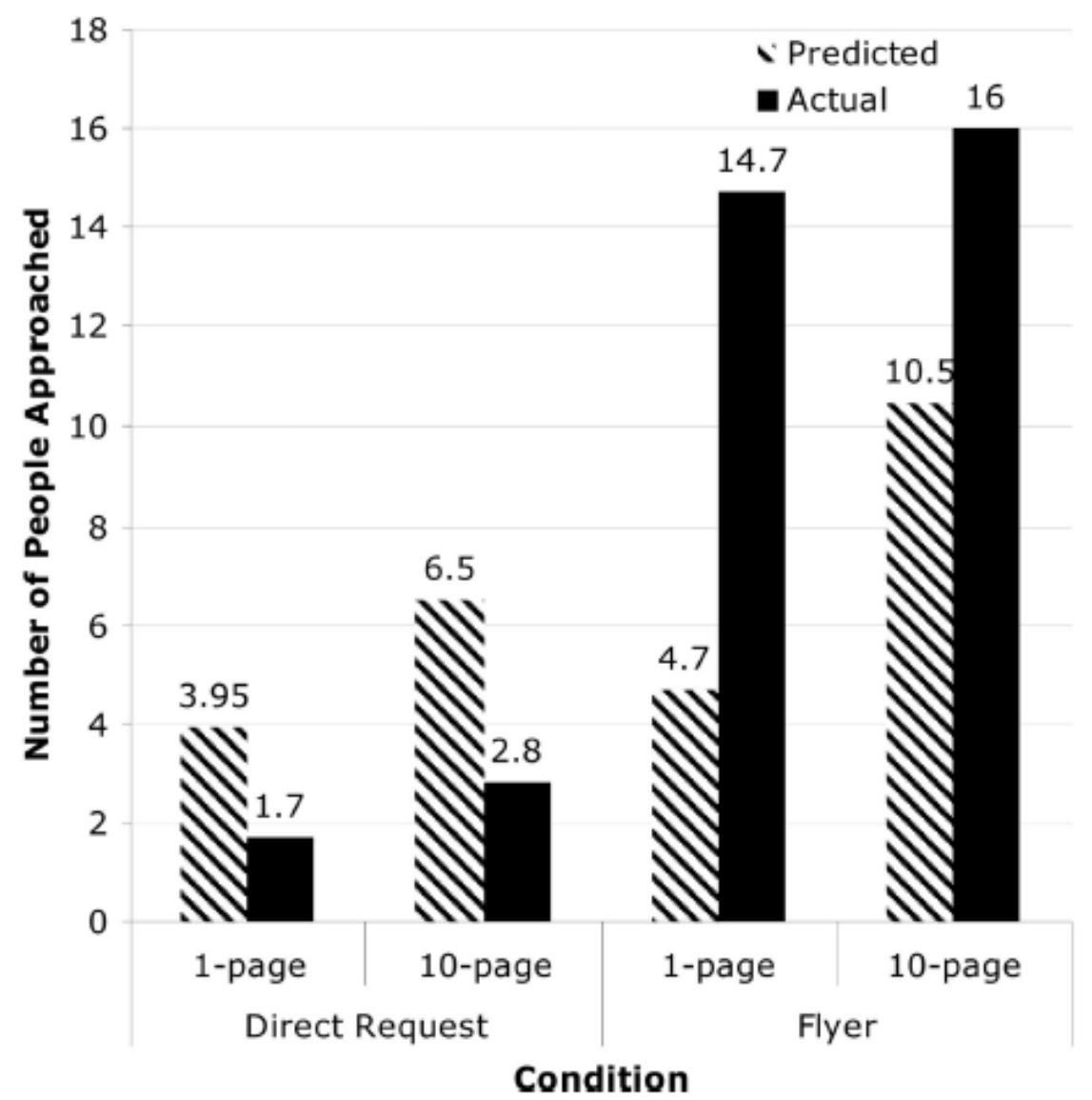

Figure 3. Predicted versus actual compliance by request directness and request-size condition in Study 6. 


\section{Predicted Compliance by Condition}

We hypothesized that participants would account more for the size of the request than they would the directness of the request when making their compliance predictions. To test this idea, we conducted a 2 (directness: direct request vs. flyer) X 2 (size: 1 page vs. 10 page) ANOVA with participants' predictions as the dependent variable. The only significant predictor of participants' predicted compliance rates to emerge from this analysis was the size of the request, $F(1,75)=$ 8.36, $p=.005$. In the 10-page questionnaire condition, participants predicted that they would have to ask (or hand flyers to) 8.49 people on average before one person would fill out a questionnaire, and in the 1-page condition, participants predicted that it would take 4.32 people on average before one person would complete a questionnaire. Participants also estimated that it would take more requests in the flyer condition $(M=7.58)$ than it would in the direct-request condition $(M=5.22)$ to get one person to fill out a questionnaire, but this difference was not significant, $F(1,75)=2.68, n s$.

\section{Actual Compliance by Condition}

We hypothesized that actual compliance would show the opposite pattern to predicted compliance-that is, we thought that the directness of the request would have more of an effect on actual compliance than the size of the request. To test this prediction, we conducted another 2 (directness: direct request vs. flyer) X 2 (size: 1 page vs. 10 page) ANOVA, this time with actual compliance as the dependent variable. Consistent with our hypothesis, the only significant predictor that emerged in this analysis was request directness, $F(1,75)=75.28, p<.001$. When making the request directly, participants had to ask only 2.28 people in order to get one person to fill out a questionnaire, but when making the request via flyers, participants had to hand out 15.33 flyers in order to get one person to complete a questionnaire. The size of the request (1 page or 10 page) had no effect on actual compliance rates $(F<1)$.

\section{Perceived Social Costs and Accuracy of Compliance Judgments}

We also had participants rate how difficult, awkward, and embarrassing they thought it would be for someone to say "no" to their requests for help. According to our hypothesis, participants' ratings of how difficult it is to say "no" to their requests should make their compliance predictions more or less accurate depending on the directness condition to which they were assigned. In the direct-request conditions, it was difficult for people to say "no" to participants' requests (i.e., there were high face-saving costs to saying "no"). Therefore, in these conditions, participants who rated their requests as highly difficult to refuse should have been more accurate in their predictions of compliance. However, in the flyer conditions, it was easy for people to say "no" to the request to fill out a questionnaire (i.e., there were low face-saving costs to saying "no"). Thus, participants who thought it was difficult to say "no" to their requests in these conditions should have been less accurate in their predictions of compliance.

To test this prediction, we created a measure of prediction error by subtracting actual compliance from predicted compliance and calculating the absolute value of these scores. We then looked at the correlation between our perceived social-costs scale and our prediction-error variable across the two directness conditions. In the direct-request condition, perceived social costs were negatively correlated with error, $r(40)=-.273, p=.088$. This suggests that the more discomforting participants thought it was for people to say "no" to their requests for help in this condition, the more 
accurate their predictions of compliance were. However, in the flyer condition, difficulty in saying "no" was positively correlated with error, $\mathrm{r}(39)=.266, p=.10$, suggesting that the more difficult participants thought it was for people to say "no" to their requests in these conditions, the less accurate their predictions were (these correlations are significantly different from one another, $p=.022$ ).

\section{Discussion}

In a live interaction, we demonstrate once again that potential helpers are more attuned to the face-saving costs of saying "no" to a request for help than are help seekers. Although actual compliance rates were dramatically affected by the directness of a request (high or low social cost to saying "no"), predicted compliance rates were not. Moreover, predicted compliance rates were affected by the size of the request, but actual compliance rates were not. This latter finding provides some initial support for the idea that help seekers attend more to the instrumental costs of saying "yes" to a request for help when estimating the likelihood of compliance. Further, the ability to account for potential helpers' feelings of discomfort corresponded to the accuracy with which help seekers estimated compliance. Taken together, these findings provide strong evidence for our specific predictions and overall theoretical arguments.

\section{General Discussion}

Help seeking has been described as an uncomfortable, if not embarrassing, act that requires a modicum of courage (Shapiro, 1983). In addition to appearing inadequate or incompetent, most people fear the possibility of rejection. Thus, before posing any request, help seekers are motivated to consider whether the potential helper will agree to it (DePaulo, 1982). If they suspect this person will not be inclined to say "yes," many help seekers will refrain from requesting help because they would rather avoid being rejected. But, do we get it right? That is, are we able to judge accurately whether others will reject us and our requests for assistance, thereby saving ourselves some embarrassment? Or, do we tend to underestimate others, particularly their willingness to comply with our direct requests for help? In the present research, we examined this issue in a series of studies that highlighted our tendency to underestimate others' willingness to agree to a direct request for help and an underlying psychological explanation for this bias.

In our first three studies, we asked participants to predict the likelihood that others would comply with a direct request for assistance and then had the participants make the request on their own. The nature of the request varied across studies. In two studies, the participants asked a stranger to complete a questionnaire, to loan the use of a cell phone, or to escort the participant to a specific destination. In each case, participants underestimated by as much as $50 \%$ the likelihood that others would agree to the direct request for help. In contrast, the third study involved a naturally occurring favor request. People voluntarily asked others (some they knew very well) to contribute money on their behalf to a charitable organization. Again, the participants' predicted rate of compliance fell significantly below the actual rate. That is, people were more willing to offer help in response to a direct request than our participants had assumed they would be.

We examined a specific psychological explanation for this underestimation effect-a failure on the part of help seekers 
to consider the potential helper's discomfort, particularly the difficulty he or she may have saying "no" to a direct request for help. Denying a request for help can be awkward and embarrassing because it violates a social norm to assist those in need. Our findings suggest that help seekers may not attend to this social pressure to offer compliance. In Studies 4 and 5, we assigned people to adopt the perspective of either the help seeker or the potential helper. Those in the help-seeker role were less likely to acknowledge the discomfort that people faced in responding to direct requests for help (i.e., gave lower estimates of how difficult, awkward, or embarrassing it is to say "no"), which, in turn, corresponded to their relatively lower estimates of whether others would offer compliance.

In our final study, we replicated and extended these findings in a live interaction. Once again, we demonstrated how help seekers fail to adequately account for social pressure in estimating the likelihood of compliance. In addition, we explored what help seekers do account for in making their estimates. Specifically, we examined whether help seekers attend to instrumental costs (i.e., the time and effort required to perform a favor) in predicting whether others will agree with their requests for help. According to our results, it seems that in assessing whether a target will agree to provide help, people pay more attention to the instrumental cost of saying "yes" rather than the social cost of saying "no" (i.e., the potential embarrassment a target might feel for rejecting a request).

Taken together, these results shed new light on the subject of helping behavior, particularly the matter of estimating others' willingness to comply with direct requests for help. People often rely on assistance from others to achieve their personal, social, and professional objectives, but such assistance may not be offered spontaneously (Flynn, 2003). Instead, help seekers typically bear the responsibility of requesting assistance, something they may dread because they fear rejection. The findings from the present research suggest that this fear of rejection is somewhat unfounded. Instead, people are more willing to help than others assume, although their interest in helping may be driven by face-saving needs rather than altruistic motives.

\section{Theoretical Contributions}

The link between embarrassment and help seeking has a rich history in theory and research on helping behavior. For example, in a classic study (for a rich description of this study, see Blass,

2004) , Milgram instructed several of his graduate students to ask fellow subway passengers to give up their seats. His students found the exercise unnerving and, in one case, even nauseating. In general, research that examines how the fear of embarrassment acts as a deterrent to help seeking has focused almost exclusively on the help-seeker's perspective (e.g., DePaulo, Dull, Greenberg, \& Swaim, 1989; Friedman, 1980; Nadler \& Fisher, 1986; Phillips \& Bruch, 1988; Shapiro, 1983). However, we suggest that the helper's fear of embarrassment (induced by social pressure to adhere to an implicit norm of benevolence) might be another critical determinant of helping.

Our findings resonate with recent research on egocentrism and estimating the likelihood of helping behavior or the magnitude of helpful contributions (e.g., Epley \& Dunning, 2000; Savitsky et al., 2005). These studies demonstrated that people believe they are more charitable, on average, than are their peers. Findings from the present research complement this work-people not only overestimate their own charitable contributions but underestimate others' as well (cf. Epley \& Dunning, 2000). Further, the underestimation of compliance is rooted in an egocentric perspective, whereby people pay 
less attention to, or fail to fully appreciate, the social pressure that often leads people to offer compliance. This link to the egocentric literature may suggest several conditions that enhance or diminish the underestimation effect, including similarity (Ames, 2004), time pressure (Epley et al., 2004), and target ambiguity (Dunning, Leuenberger, \& Sherman, 1995).

\section{Future Directions}

There are many possible directions for future research to take. For example, we have suggested that help seekers may overlook another person's concern with rejecting help requests and losing face. However, a parallel bias might also existthose who are the targets of help requests may overestimate how inclined others are to request their help because they misjudge, or fail to consider, how embarrassing it would be to ask. A teacher might assume that a struggling student will seek his tutelage and, if it is not sought out, label the student as lacking interest and motivation. A supervisor could encounter a similar problem with her subordinates-expecting them to seek her advice but failing to recognize their fears of appearing incompetent. Future researchers might extend our findings by examining whether the failure to consider others' fear of embarrassment leads potential helpers to overestimate others' willingness to request their help, just as it leads help seekers to underestimate potential helpers' willingness to provide help.

An additional question worthy of future research is whether culture plays a role in the process of estimating compliance. Past research on cultural differences in help seeking suggests that a strong emphasis on self-reliance in American culture encourages U.S. citizens to withhold their requests for assistance (Nadler, 1983). Indeed, a study by Graf, Freer, and Plaizier (1979) found that help-seeking requests posed by Americans were judged more harshly by fellow Americans than were the same requests posed and judged by Dutch citizens, purportedly because Dutch citizens were less likely to enforce a norm of self-reliance. Perhaps a strong concern with appearing self-reliant leads Americans to underestimate compliance because they focus more heavily on the imposition involved in a request for help. This concern with making an imposition might lower Americans' estimates of compliance more, relative to help seekers from other cultures.

Finally, the question remains whether an accurate understanding of others' willingness to offer help will embolden people to request help. That is, if help seekers think they are more likely to get assistance, will they necessarily be more likely to ask for it? The answer might depend on the help seeker and their understanding of the potential helper's motivation. If a help seeker appreciates a potential helper's difficult circumstances - not necessarily wanting to help but wanting to avoid embarrassment-she might empathize with the potential helper's plight and hold off on making a request. Whether the help seeker becomes more or less emboldened to request help could depend on her level of empathy. For those who are more attuned and sensitive to the potential helper's circumstances, they may be disinclined to ask for help if it means taking advantage of another individual's difficult position and causing that person some discomfort (cf. Nadler, 1983; Shapiro, 1983). Studies that account for the help- seeker's empathic disposition are needed to test this idea.

A related issue is the potential downside of asking for help when the helpful act is driven by a strong motivation to avoid feelings of discomfort. On one hand, if the helper believes her motivation for complying with a request for help is to adhere to social pressure (rather than her altruistic inclinations), she may feel "trapped" and subsequently resent the help-seeker's imposition. Thus, people may be worse off if accurately estimating compliance motivates them to ask for 
more help-they might receive more assistance but simultaneously elicit animosity. On the other hand, some research suggests that when we help someone, we may be inclined to justify this action by convincing ourselves that the receiver is an attractive, likable, and deserving person (e.g., Jecker \& Landy, 1969). Future researchers might attempt to reconcile these conflicting viewpoints-to test whether or not those who are aware of the social pressure that potential helpers face and take advantage of it will eventually encounter a backlash in the form of lower levels of liking and trust.

\section{Conclusion}

No one likes being rejected. As a result, we avoid requesting assistance from those who we think will not agree to provide it. But are we accurate in estimating whether others will be willing to comply with our requests for help, or do we wrongly assume that we will be rejected when this is not the case? We find that people generally underestimate the likelihood of compliance in making a direct request for help, in part, because they fail to fully appreciate that although it is difficult for help seekers to risk rejection, it is also difficult for potential helpers to offer rejection. Recognizing and overcoming this paralyzing, and in many cases unfounded, fear may bear meaningful consequences, not just for individuals but for the good deeds they hope to accomplish. The Leukemia and Lymphoma Society, specifically, might be more successful in raising money to support cancer research if its volunteers' expectations of success in soliciting donations were more accurate. More generally, success in help seeking may be more likely than we tend to assume.

\section{References}

Ames, D. R. (2004). Strategies for social inference: A similarity contingency model of projection and stereotyping in attribute prevalence estimates. Journal of Personality and Social Psychology, 87(5), 573-585.

Baron, R. M., \& Kenny, D. A. (1986). The moderator-mediator variable distinction in social psychological research: Conceptual, strategic, and statistical considerations. Journal of Personality and Social Psychology, 51, 1173-1182.

Batson, C. D., Early, S., \& Salvarani, G. (1997). Perspective taking: Imagining how another feels versus imagining how you would feel. Personality and Social Psychology Bulletin. 23(7), 751-758. Baumeister, R. F., Stillwell, A. M., \& Heatherton, T. F. (1994). Guilt: An interpersonal approach. Psychological Bulletin, 115, 243-267.

Blass, T. (2004). The man who shocked the world: The life and legacy of Stanley Milgram. New York: Basic Books.

Blau, P. (1955). The dynamics of bureaucracy. Chicago: University of Chicago Press.

Brown, P., \& Levinson, S. (1987). Politeness: Some universals in language usage. Cambridge, MA: Cambridge University Press.

DePaulo, B. (1982). Social psychological processes in informal helpseeking. In T. A. Wills (Ed.), Basic processes in helping relationships (pp. 255-279). New York: Academic Press.

DePaulo, B. (1983). Perspectives on help-seeking. In B. DePaulo, A. Nadler, \& J. Fisher (Eds.), New directions in helping: Vol. 2. Help seeking (pp. 3-12). New York: Academic Press.

DePaulo, B., Dull, W., Greenberg, J., \& Swaim, G. (1989). Are shy people reluctant to ask for help? Journal of Personality 
and Social Psychology, 56, 834-844.

DePaulo, B., \& Fisher, J. (1980). The costs of asking for help. Basic and Applied Social Psychology, 1, 23-35.

Downey, G., \& Feldman, S. (1996). Implications of rejection sensitivity for intimate relationships. Journal of Personality and Social Psychology, 70, 1327-1343.

Dunning, D., Leuenberger, A., \& Sherman, D. (1995). A new look at motivated inference: Are self-serving theories of success a product of motivational forces? Journal of Personality and Social Psychology, 59, 58-68. Epley, N., \& Dunning, D. (2000). Feeling "holier than thou": Are self-serving assessments produced by errors in self- or social prediction? Journal of Personality and Social Psychology, 79, 861-875.

Epley, N., Keysar, B., Van Boven, L., \& Gilovich, T. (2004). Perspective taking as egocentric anchoring and adjustment. Journal of Personality and Social Psychology, 87, 327-339.

Flynn, F. (2003). What have you done for me lately? Temporal changes in subjective favor evaluations. Organizational Behavior and Human Decision Processes, 91(1), 38-50.

Flynn, F. J., \& Brockner, J. (2003). It's different to give than to receive: Asymmetric reactions of givers and receivers to favor exchange. Journal of Applied Psychology, 88(6), 1-13.

Friedman, P. (1980). Shyness and reticence in students. Washington, DC: National Education Association.

Gergen, K., Ellsworth, P., Maslach, C., \& Seipel, M. (1975). Obligation, donor resources, and reactions to aid in three nations. Journal of Personality and Social Psychology, 3, 390-400.

Gilbert, D. T., \& Malone, P. S. (1995). The correspondence bias. Psychological Bulletin, 117, 21-38.

Goethals, G. R. (1986). Fabricating and ignoring social reality: Self-serving estimates of consensus. In J. M. Olson, C. P. Herman, \& M. P. Zanna (Eds.), Social comparison and relative deprivation: The Ontario symposium (Vol. 4, pp. 135-157). Hillsdale, NJ: Erlbaum.

Goffman, E. (1955). On face-work. Psychiatry, 18, 213-231.

Goffman, E. (1971). Relations in public. New York: Basic Books.

Gouldner, A. (1960). The norm of reciprocity: A preliminary statement. American Sociological Review, 25, 161-179.

Graf, R., Freer, S., \& Plaizier, P. (1979). Interpersonal perception as a function of help-seeking. Journal of Cross-Cultural Psychology, 18, 101-110.

Greenberg, M. S. (1980). A theory of indebtedness. In K. Gergen, M. Greenberg, \& R. Willis (Eds.), Social exchange: Advances in theory and research (pp. 3-26). New York: Plenum.

Greenwald, A. G., Carnot, C. G., Beach, R., \& Young, B. (1987). Increasing voting behavior by asking people if they expect to vote. Journal of Applied Psychology, 72, 315-318.

Gross, A. E., \& Somersan, S. (1974, November). Helper effort as an inhibitor of help-seeking. Paper presented at the annual meeting of the Psychonomic Society, Boston, MA.

Jecker, J., \& Landy, D. (1969). Liking a person as a function of doing him a favor. Human Relations, 22, 371-378.

Latane, B., \& Darley, J. M. (1970). The unresponsive bystander: Why doesn't he help? New York: Appleton-Century-Crofts. Lee, F. (1997). When the going gets tough, do the tough ask for help? Help seeking and power motivation in organizations. Organizational Behavior and Human Decision Processes, 72, 336-363. 
Milgram, S., \& Sabini, J. (1978). On maintaining urban norms: A field experiment in the subway. In A. Baum, J. E. Singer, \& S. Valins (Eds.), Advances in environmental psychology: Vol. 1 (pp. 31-40). Hillsdale, NJ: Erlbaum.

Miller, D., \& Ratner, R. K. (1998). The disparity between the actual and assumed power of self-interest. Journal of Personality and Social Psychology, 74, 53- 62.

Nadler, A. (1983). Personal characteristics and help-seeking. In B. De- Paulo, A. Nadler, \& J. Fisher (Eds.), New directions in helping: Vol. 2. Help seeking (pp. 303-340). New York: Academic Press.

Nadler, A., \& Fisher, J. (1986). The role of threat to self-esteem and perceived control in recipient reactions to aid: Theory development and empirical validation. In L. Berkowitz (Ed.), Advances in experimental social psychology (Vol. 19, pp. 8183). New York: Academic Press.

Nickerson, R. S. (1999). How we know-and sometimes misjudge-what others know: Imputing one's own knowledge to others. Psychological Bulletin, 125, 737-759.

Phillips, S., \& Bruch, M. (1988). Shyness and dysfunction in career development. Journal of Counseling Psychology, 35, 159165.

Pruitt, D. G. (1968). Reciprocity and credit building in a laboratory dyad. Journal of Personality and Social Psychology, 8 , 143-147.

Ross, L. (1977). The intuitive psychologist and his shortcomings: Distortions in the attribution process. In L. Berkowitz (Ed.), Advances in experimental social psychology (Vol. 10, pp. 173-220). New York: Academic Press.

Sabini, J., Siepmann, M., \& Stein, J. (2001). The really fundamental attribution error in social psychological research. Psychological Inquiry, 12, 1-15.

Savitsky, K., Epley, N., \& Gilovich, T. (2001). Is it as bad as we fear?: Overestimating the extremity of others' judgments. Journal of Personality and Social Psychology, 81, 44-56.

Savitsky, K., Van Boven, L., Epley, N., \& Wight, W. (2005). The unpacking effect in responsibility allocations for group tasks. Journal of Experimental Social Psychology, 41, 447-457.

Shapiro, E. G. (1983). Embarrassment and help-seeking. In B. DePaulo, A. Nadler, \& J. Fisher (Eds.), New directions in helping: Vol. 2. Help seeking (pp. 143-163). New York: Academic Press.

Sherman, S. J. (1980). On the self-erasing nature of errors of prediction. Journal of Personality and Social Psychology, 39, 211-221.

Swim, J., Scott, E., Sechrist, G., Campbell, B., \& Stangor, C. (2003). The role of intent and harm in judgments of prejudice and discrimination. Journal of Personality and Social Psychology, 84, 944 -959.

Thibaut, J., \& Kelley, H. (1959). The social psychology of groups. New Brunswick, NJ: Transaction Publishers.

Woodzicka, J., \& LaFrance, M. (2001). Real versus imagined sexual harassment. Journal of Social Issues, 57, 15-30. 